Revista Signos

2008, 41(67)

$131-134$

\section{Discurso de recepción al Doctor Giovanni Parodi Sweis como Miembro Correspondiente por Valparaíso de la Academia Chilena de la Lengua}

Valparaíso, 18 de abril, 2008

\title{
Marianne Peronard
}

Miembro de Número, Academia Chilena de la Lengua

Pontificia Universidad Católica de Valparaíso

Chile

Me ha tocado el placer de recibir como miembro correspondiente de la Academia Chilena de la Lengua al profesor titular de la Pontificia Universidad Católica de Valparaíso, Doctor Giovanni Parodi Sweis. Se trata de una persona que reúne, en alto grado, dos cualidades que rara vez se dan en una misma persona. Por una parte tiene las características propias de un enérgico ejecutivo con visión de futuro, que ha logrado, gracias a su fuerza y entusiasmo, llevar nuestros Programas de Postgrado a niveles de excelencia con acreditación máxima, actuando, no solo como un buen organizador sino también como un verdadero motor de quienes lo acompañan.

Por ello no le resultó fácil la decisión que tuvo que tomar en sus primeros años de profesional, rechazando una tentadora oferta para un alto cargo directivo en una universidad particular. Ello demostró que desde muy temprano sabía muy bien lo que quería e intuía lo que podía hacer de su vida.

Por otra parte, su aparentemente inacabable energía, le ha permitido destacarse como estudioso e investigador tanto a nivel nacional como internacional. Es esta última característica la que quisiera resaltar en este momento, pues es ella la que lo hace merecedor del honor que significa pertenecer a la Academia de la Lengua. El Doctor Parodi ha hecho toda su carrera académica en nuestra Universidad. En el año 1986 recibió el título de Profesor de Inglés y el grado de Licenciado en Lengua y Literatura Inglesa. Su interés y probada capacidad en esta asignatura le permitieron ganar el concurso interno como ayudante de Gramática Inglesa. Cuatro años después, logró el grado de Magíster en Lingüística Aplicada.

Con ello, dio inicio a sus crecientes actividades como investigador en el área del lenguaje, sin dejar de lado su docencia en gramática inglesa. Así lo prueba su participación entre los años 1990-1991 como co-investigador en un proyecto de 
investigación de la Dirección General de Investigación de la UCV, titulado "Proposición de un sílabo para la enseñanza del idioma inglés en la educación superior". Anteriormente, ya había mostrado su inclinación por la investigación en el área de la psicolingüística, participando como co-investigador en el proyecto FONDECYT, "Comprensión de textos escritos en alumnos de $7^{\circ} \mathrm{y}$ $8^{\circ}$ años de Educación Básica". A partir de ese momento su interés se orienta hacia los estudios acerca del uso (comprensión y producción) del castellano, participando como co-investigador en cuatro proyectos FONDECYT: "Comprensión de textos escritos en alumnos de $7^{\circ}$ y $8^{\circ}$ años de Educación Básica", "Estrategias de comprensión lingüística en alumnos de Educación Básica y Media: Uso y enseñanza", "La macroestructura y la metacognición en la comprensión de textos escritos" y "Autorregulación de los procesos de comprensión de textos escritos".

En el año 1998 prueba sus alas, presentando como Investigador Responsable un proyecto financiado por la Dirección General de Investigación de la Universidad sobre el mismo tema, a saber, "Diseño y elaboración de pruebas de comprensión y producción de textos escritos". Desde entonces y como investigador responsable y siempre en la misma línea, ha presentado y ganado, en forma consecutiva, los siguientes proyectos FONDECYT: "Conexiones entre comprensión y producción de textos escritos en alumnos de Educación Básica" y "Hacia un perfil de la competencia estratégica escrita en alumnos de educación básica y media".

Estudioso incansable, se ha mantenido permanentemente al día en los avances que se producen a nivel internacional en las ciencias del lenguaje. Esto se refleja en los nuevos proyectos de investigación que presentó como investigador responsable, relacionados con el concepto de género lingüístico -entendido como variedades de una misma lengua según el dominio científico o profesional, la naturaleza del hipotético destinatario y la importancia que tiene el lenguaje en determinado contexto comunicativo- (por ejemplo, el castellano que usan los médicos es distinto al que usan los ingenieros; el lenguaje que usa un médico cuando habla con un colega es distinto a la forma que utiliza con un paciente; el cuidado que pone al escribir acerca de una enfermedad es distinto a su explicación oral de la misma en una conversación cara a cara).

Manifestaciones de este nuevo interés son, por ejemplo, los proyectos FONDECYT de investigación: "El análisis del discurso científico y su comprensión lingüística en la formación técnico profesional", "Discurso académico, discurso profesional: Lingüística de corpus", y el proyecto internacional ECOS/CONICYT: "Ciencias del lenguaje y géneros del discurso".

El primero de estos proyectos es un especie de puente entre su antigua motivación por la psicolingüística y su nuevo interés por los géneros discursivos, mientras que el segundo evidencia su interés por usar los avances tecnológicos en sus investigaciones acerca de las variedades intralingüísticas. En efecto, los lingüistas, inquietos por la excesiva generalización imperante en los estudios descriptivos, basados a menudo en unos pocos ejemplos, que en ocasiones son inventados por el propio investigador como hablante nativo de la lengua que se investiga, comienzan a 
utilizar enormes conjuntos de datos recogidos de la realidad e ingresados a computadoras para ser procesados mecánicamente gracias a programas especialmente preparados para ello. De hecho, me atrevería a decir que Giovanni Parodi es el precursor del desarrollo de este paradigma investigativo en nuestro país y en Latinoamérica.

Hay otra característica que es necesario resaltar de este destacado lingüista y es su clara concepción en cuanto a que si se desea producir algún impacto a nivel científico es necesario, no solo difundir los propios hallazgos, sino además formar comunidades que compartan sus bases teóricas, lo que implica formar discípulos que trabajen en equipo. Lo primero, es decir, su interés por difundir el producto de sus investigaciones, queda claramente demostrado por su constante asistencia a congresos, coloquios y encuentros internacionales en Chile y en el extranjero (Madrid, Brasil, España, México, Cuba, Argentina, Puerto Rico, Colombia, Estados Unidos de Norteamérica y Australia), en los que ha presentado ponencias y comunicaciones sobre los asuntos investigados. Como es bien sabido, dichas actividades ofrecen la oportunidad de entrar en contacto personal con otros investigadores en áreas afines.

Otra forma que ha elegido para la divulgación de los productos de sus investigaciones ha sido la publicación de alrededor de treinta y cinco artículos en estos pocos años, que han aparecido en las principales revistas nacionales, tales como la Revista de Lingüística Aplicada, Estudios Filológicos, Revista Signos. Estudios de Lingüística, Boletín de Lingüística, Revista de Lingüística Teórica y Aplicada, así como en revistas extranjeras: Revista Española de Lingüística, Revista Ibericana de Discurso y Sociedad, Reading \& Writing Interdisciplinary Journal, por nombrar solo algunas.

Lo segundo, es decir, la necesidad que siente de unir fuerzas y formar equipos se evidencia en la generosa invitación a jóvenes lingüistas para que lo acompañen en sus proyectos de investigación, invitación que ya comenzó a mostrar sus frutos en publicaciones propias por parte de estos co-investigadores y colaboradores. Otra clara manifestación de su concepto de lo que es hacer ciencia está demostrado por los libros en los que, a comienzos de sus actividades como investigador, ha colaborado con artículos acerca de la comprensión y producción del castellano, para culminar en el año 1999 con un libro propio acerca de la comprensión de textos escritos.

Posteriormente, en el año 2007, sus actividades tomaron un nuevo rumbo al publicar, esta vez como editor, obras que reúnen trabajos relacionados con sus nuevos intereses, tales como Working with Spanish corpora publicado en Londres, "Lingüística de corpus y discursos especializados: Puntos de mira", publicado en Valparaíso y Lingüística de Corpus, en revisión en España. Estas publicaciones reúnen artículos de autores chilenos y extranjeros que gustosamente han aceptado colaborar con él con escritos inéditos y que a su vez le han extendido invitaciones para colaborar con artículos en libros editados por ellos, como por ejemplo Genre in a changing world. Writing across the currículo editado por Bazerman, Bonini y Figueiredo, y Discourse, of course editado en Ámsterdam por Renkema. 
Todas estas publicaciones le han dado a Giovanni Parodi un merecido renombre como lingüista de primera línea a nivel latinoamericano e, incluso entre especialistas españoles. Ello le ha valido numerosas invitaciones para dictar cursos, seminarios, talleres y mesas redondas en Universidades de Puebla, Buenos Aires, Caracas, Mendoza, Madrid, Barcelona, San Juan, Cali, Cuyo, Barquisimeto, Córdoba, Sydney Memphis.

A lo anterior cabe agregar diversas estadías en universidades extranjeras lo que le ha permitido conocer, de primera mano, los trabajos que realizan destacados especialistas, expandiendo así sus perspectivas académicas y disciplinarias, las que a su vuelta a Chile ha entregado generosamente a los alumnos de los postgrados de Magíster en Lingüística Aplicada y Doctorado en Lingüística que imparte nuestra Universidad bajo su dirección, tanto a través de los cursos dictados por él como gracias a las quince tesis de grado que ha guiado.

No quiero, sin embargo, seguir enumerando todas las actividades, publicaciones y éxitos de este, para mí, joven lingüista; ni, como dije anteriormente, mencionar todos los logros alcanzado gracias a su gran habilidad como gestor académico que ha llevado los estudios de postgrado en lingüística de nuestra universidad a niveles muy destacado a nivel nacional y latinoamericano.

No obstante, creo que aún es necesario enfatizar que lo que ha contribuido al renombre de Giovanni Parodi como profesor e investigador en el campo de la lingüística, no es solamente la cantidad de publicaciones o su frecuente asistencia a Congresos, que le han permitido establecer excelentes contactos con los principales cultivadores de las ciencias del lenguaje, sino sobre todo, la calidad y actualidad de su contribución al desarrollo de los estudios del lenguaje en nuestro país.

En fin, no hay dudas de que su incansable y variada actividad en el campo de la lingüística y su difusión hacia nuevas generaciones parece contradecir el refrán que dice "El que mucho abarca, poco aprieta".

Por todo lo anterior, no es de extrañar que la Academia haya acordado, por unanimidad, invitar al Dr. Giovanni Parodi Sweis a integrar sus filas como miembro correspondiente por Valparaíso. 